\title{
Multi-Directional Local Search for Sustainable Supply Chain Network Design
}

\author{
Majid Eskandarpour ${ }^{a, b}$, Pierre Dejax ${ }^{c}$, Olivier Péton ${ }^{c}$ \\ ${ }^{a}$ IESEG School of Management, 3 rue de la Digue, 59000 Lille, France \\ ${ }^{b}$ LEM-CNRS 9221, 3 rue de la Digue, 59000 Lille, France \\ ${ }^{c}$ IMT Atlantique, LS2N UMR CNRS 6004 (Laboratoire des Sciences du Numérique de Nantes), 4 rue Alfred \\ Kastler, F-44307 Nantes Cedex, France
}

\begin{abstract}
In this paper, we propose a bi-objective MILP formulation to minimize logistics costs as well as $\mathrm{CO}_{2}$ emissions in a supply chain network design problem with multiple layers of facilities, technology levels and transportation mode decisions. The proposed model aims at investigating the trade-off between cost and $\mathrm{CO}_{2}$ emissions through supply chain activities (i.e., raw material supply, manufacturing, warehousing, and transportation). To this end, a multi-directional local search (MDLS) metaheuristic is developed. The proposed method provides a limited set of non-dominated solutions ranging from a purely cost effective solution to a purely environmentally effective one. Each iteration of the MDLS consists in performing local searches from all non-dominated solutions. To do so, a Large Neighborhood Search (LNS) algorihtm is used. Extensive experiments based on randomly generated instances of various sizes and features are described. Three classic performance measures are used to compare the set of non-dominated solutions obtained by the MDLS algorithm and by directly solving the MILP model with the epsilon-constraint approach. This paper is concluded by managerial insights about the impact of using greener technology on the supply chain
\end{abstract}

\footnotetext{
${ }^{*}$ Corresponding author. Olivier Péton, IMT Atlantique, 4 rue Alfred Kastler, F-44300 Nantes, France. olivier.peton@imt-atlantique.fr, +33251 858313
}

Preprint submitted to International Journal of Production Research

October 4, 2019 
topology.

Keywords: FACILITY LOCATION; SUSTAINABLE SUPPLY CHAIN ; SUPPLY CHAIN DESIGN ; LARGE NEIGHBORHOOD SEARCH ; MULTI DIRECTIONAL LOCAL SEARCH 


\title{
Multi-Directional Local Search for Sustainable Supply Chain Network Design
}

\author{
Majid Eskandarpour ${ }^{a, b}$, Pierre Dejax ${ }^{c}$, Olivier Péton ${ }^{c}$ \\ ${ }^{a}$ IESEG School of Management, 3 rue de la Digue, 59000 Lille, France \\ ${ }^{b}$ LEM-CNRS 9221, 3 rue de la Digue, 59000 Lille, France \\ ${ }^{c}$ IMT Atlantique, LS2N UMR CNRS 6004 (Laboratoire des Sciences du Numérique de Nantes), 4 rue Alfred \\ Kastler, F-44307 Nantes Cedex, France
}

\section{Introduction}

In this paper, we consider a Supply Chain Network Design (SCND) problem with fourlayers and multiple commodities. This SCND model considers the locations of facilities at the two intermediate layers: production facilities and distribution centers. It also determines the choice between several technology levels at any facility and transportation modes on every arc of the network.

Technology levels and transportation modes highly influence the level of $\mathrm{CO}_{2}$ emissions. The use of "green" technology may reduce the amount of $\mathrm{CO}_{2}$ emissions through supply chains. Green technology might be achieved by deploying technology principles such as renewable energy, renewable raw materials, life-cycle assessment, biotechnology approach, and so forth (Doble and Kruthiventi, 2007). For example, within the biomass supply chain, fast pyrolysis followed by hydroprocessing as the biomass conversion technology is more effective in reducing GHG emissions over gasification followed by Fischer-Tropsch synthesis (Gao and You, 2017).

\footnotetext{
${ }^{*}$ Corresponding author. Olivier Péton, IMT Atlantique, 4 rue Alfred Kastler, F-44300 Nantes, France. olivier.peton@imt-atlantique.fr, +33251858 313
}

Preprint submitted to International Journal of Production Research

October 4, 2019 
Supply chain network design has mostly incorporated four policies to integrate environmental issues: carbon cap, carbon offset, cap-and-trade and carbon tax. All four policies succeed to achieve substantial emission reductions with a slight increase in total cost; mostly by configuring the supply chain to use lower-emitting resources (Waltho et al., 2019). However, such compromise solutions can be easily missed using traditional single objective methods 20 (Harris et al., 2014).

Therefore, we consider a mixed integer linear program (MILP) with two objectives. The first objective function is the minimization of logistics costs expressed as the sum of facility fixed costs, production costs, and transportation costs. The second objective is the minimization of $\mathrm{CO}_{2}$ emissions arising from production and logistics operations.

Although supply chain network design is intrinsically a multi-objective problem, the number of multi-objective SCND related publications has grown up quite lately. They represent only $9 \%$ of the papers cited in the review by Melo et al. (2009) about facility location and supply chain management. In their survey on multiple criteria facility location problems, Zanjirani Farahani et al. (2010), studied 730 source titles. Since then, the field has known a tremendous growth, mainly due to the huge literature in sustainable supply chain (Eskandarpour et al., 2015). Customer service and risk related objectives are also more and more studied.

The literature on multi-objective optimization often distinguishes between single-solution methods and methods providing decision makers with a set of mutually non-dominated solutions.

Single-solution methods convert multi-objective formulations into single objective formulations. In this category, models with weighted sum of objectives can be solved by any classical solution methods, e.g. Tabu Search (Cardona-Valdés et al., 2014; Caballero et al., 2007), and Variable Neighborhood Search (Eskandarpour et al., 2013, 2014).

Single-solution methods can be used to find a set of mutually non-dominated solutions, 
at the price of being run multiple times with different parameters. This can become a computational burden for large instances. Therefore, developing heuristic methods is inevitable to find trade-off solutions (Zanjirani Farahani et al., 2010). Population based methods offer a choice between several trade-off solutions within a single run, providing decision makers with sufficient options necessary to balance all objectives (Guillén-Gosálbez, 2011; Harris et al., 2014). Table 1 shows examples of recent population based method references.

\begin{tabular}{ll}
\hline Meta-heuristic & Reference papers \\
\hline Genetic & Altiparmak et al. (2006); Dehghanian and Mansour (2009); Liao et al. (2011); \\
& $\begin{array}{l}\text { Demirel et al. (2014); Harris et al. (2014); Robles et al. (2016); Tiwari et al. } \\
\text { (2016); Kumar et al. (2017); Shi et al. (2017); Zhang et al. (2017); Alavidoost } \\
\\
\text { et al. (2018); Ebrahimi (2018) }\end{array}$ \\
\hline Memetic & Jamshidi et al. (2012); Pishvaee et al. (2010) \\
\hline Particle swarm & $\begin{array}{l}\text { Canales-Bustos et al. (2017); Kadambala et al. (2017); Moncayo-Martínez and } \\
\text { Mastrocinque (2016); Zhang et al. (2016); Shankar et al. (2013b,a); Ganguly } \\
\text { et al. (2011) }\end{array}$ \\
\hline Scatter search & Olivares-Benitez et al. (2013) \\
\hline NSGA II & Alizadeh Afrouzy et al. (2018); Arabzad et al. (2015) \\
\hline Hybrid & Devika et al. (2014); Govindan et al. (2015) \\
\hline
\end{tabular}

Table 1: Examples of multi-objective population based methods for SCND

The bi-objective SCND problem is solved with the multi-directional local search (MDLS) algorithm originally proposed by Tricoire (2012). MDLS is a multi-objective optimization framework which generalizes the concept of local search to multiple objectives. Its key idea is to use different local searches, each of them working on a single objective. It considers a set of non-dominated solutions, called non-dominated set, which is updated through the solution process. More precisely, a local search is performed in order to improve non-dominated solutions with respect to each objective function separately. An iteration consists in (i) selecting a solution, (ii) performing local search on this solution for each objective/direction, thus producing a new solution in each direction and (iii) accepting or rejecting the newly produced solutions. 
In Tricoire (2012), MDLS has been applied to several multi-objective problems such as the multi-objective multi-dimensional knapsack problem, the bi-objective set packing problem and the bi-objective orienteering problem. It has been later applied to intermodal train

\subsection{Problem settings}

We consider a bi-objective SCND model based on a logistics network with four layers: suppliers, production plants, distribution centers (DCs) and customers. The location of suppliers and customers are known, whereas those of plants and DCs have to be determined

Decision makers choose where to locate plants and DCs as well as which technology to 
install at selected locations. Thus, for each location, we consider a list of candidate technologies. The generic term technology may refer to distinct generations or variants of the same type of machine or to competing technological choices. Each technology has its own capacity, production cost and $\mathrm{CO}_{2}$ emissions. If a technology is less effective than another technology both from the economic and environmental point of view, it will never be selected. Thus, we consider only technologies that do not dominate each other, i.e greener technologies are considered to require a larger initial fixed cost. This is why the integration of technological choices is perfectly adapted to a bi-objective model.

As products move through the supply chain, their carbon footprint increases. Raw material sourcing, manufacturing, handling, transportation, and storage contribute to the emissions a product directly or indirectly is responsible for (Waltho et al., 2019). In particular, when it comes to investigate the source of $\mathrm{CO}_{2}$ emissions within supply chains, warehousing operations and logistics centers have received little attention (Freis et al., 2016). Warehouses 95 have significant amount of energy consumption due to lighting, heating, cooling and air conditioning as well as material handling equipment (Ries et al., 2017). Environmental assessment becomes particularly crucial in automated warehouses (Tappia et al., 2015)."

To this end, the environmental impact is assessed by the quantity of $\mathrm{CO}_{2}$ emissions in the whole network, arising from two main sources: (i) product processing, for which the amount of emissions depends on the technology installed and is assumed proportional to the amount of products processed by the facility (ii) product transportation, for which the emissions are based on the distance travelled and the type of transportation mode used. Although far from being exhaustive, this assessment is considered relevant since transport and industrial facilities account for $22 \%$ and $20 \%$ of global $\mathrm{CO}_{2}$ emissions, respectively (OECD/IEA, 2012). Moreover, it can be easily measured and integrated into mathematical models, which can explain its large use in academic papers (Wang et al., 2011).

We assume that a restricted list of suitable transportation modes has been a priori iden- 
tified for each pair of nodes, with respect to criteria such as availability and safety, shipping costs, $\mathrm{CO}_{2}$ emissions, shipment capacities, speed and frequency. Hence, for each arc, one or several transportation modes are available, such as road, rail, inland navigation or air transport. At the strategic level, the cost and emissions of most transportation modes are assumed linear with respect to the quantity carried. Some transportation modes incur a fixed charge.

With respect to the above-mentioned description, the SCND model proposed in this paper aims at determining the number, location, and technology level at plants and DCs, the suitable transportation modes, and the product flows between facilities. The goal is to minimize two conflicting objectives: the total cost and the environmental impact expressed by amount of $\mathrm{CO}_{2}$ emissions. In the following, we present the mathematical formulation of this problem, as extended from Eskandarpour et al. (2017) including $\mathrm{CO}_{2}$ emissions and technology levels.

\subsection{Data, sets, parameters and variables}

The sets, parameters and decision variables used in the mathematical model are given in Tables 2, 3 and 4 respectively. The SCND problem is defined on a directed graph $\psi=(V, A)$ where $V=I \cup J \cup K \cup L$ and the set $A$ of arcs defines all possible links between two successive layers.

\subsection{Mathematical formulation}

The economic objective (1) encompasses all fixed and variable costs in the network. The first term is the sum of all opening fixed costs. The second and third terms correspond to processing costs. The fourth term represents the fixed costs of using each transportation mode between each pair of nodes. The last term refers to the variable transportation cost between each pair of nodes. 


\begin{tabular}{ll}
\hline Set & Description \\
\hline$I$ & suppliers \\
$J$ & candidate plants \\
$K$ & candidate DCs \\
$L$ & customers \\
$J^{o} \subset J$ & open (selected) plants \\
$K^{o} \subset K$ & open (selected) DCs \\
$P$ & products \\
$M$ & transportation modes \\
$T$ & technologies \\
\hline
\end{tabular}

Table 2: Data sets

\begin{tabular}{ll}
\hline Parameter & Description \\
\hline$d_{l}^{p}$ & demand of customer $l \in L$ for product $p \in P$ \\
$c_{j}^{t}$ & fixed cost of opening a facility $j \in J \cup K$ using technology $t \in T$ \\
$a_{i}^{p}$ & unit processing cost of product $p \in P$ at supplier $i \in I$ \\
$e_{i}^{p t}$ & unit processing cost of product $p \in P$ at $i \in J \cup K$ with technology $t \in T$ \\
$c a p_{i}$ & capacity of facility $i \in I \cup J \cup K$ \\
\hline$g_{i j}^{m}$ & fixed cost of using transportation mode $m \in M$ along arc $(i, j) \in A$ \\
$v_{i j}^{m p}$ & variable transportation cost of a unit of product $p \in P$ on arc $(i, j) \in A$ \\
& by mode $m \in M$ \\
$\underline{V}_{i j}^{m}$ & minimum threshold volume for using transportation mode $m \in M$ along \\
$\bar{V}_{i j}^{m}$ & arc $(i, j) \in A$ \\
\hline$b_{i}^{p}$ & capacity of transportation mode $m \in M$ along arc $(i, j) \in A$ \\
$q_{i}^{p t}$ & unitary $\mathrm{CO}_{2}$ emissions at supplier $i \in I$ for each product $p \in P$ \\
& $\mathrm{CO}_{2}$ emissions caused by the manufacturing or warehousing of one unit \\
$r_{i j}^{m p}$ & product $p \in P$ at $j \in J \cup K$ with technology $t \in T$ \\
& $\mathrm{CO}_{2}$ emissions caused by the transportation of one unit of product $p \in P$ \\
& along arc $(i, j) \in A$ by mode $m \in M$ \\
\hline
\end{tabular}

Table 3: Parameters 


\begin{tabular}{lll}
\hline Name & Type & Description \\
\hline$y_{j}^{t}$ & binary & $=1$ if facility $j \in J \cup K$ with technology level $t$ is open and 0 \\
& otherwise \\
& $=1$ if transportation mode $m \in M$ is selected for $\operatorname{arc}(i, j) \in A$ and \\
$u_{i j}^{m}$ & binary & 0 otherwise \\
$x_{i j}^{m p}$ & continuous & flow of product $p \in P$ on arc $(i, j) \in A$ using transportation mode \\
& $m \in M$
\end{tabular}

Table 4: Decision variables

$$
\begin{array}{r}
\min z_{1}=\sum_{j \in J \cup K} \sum_{t \in T} c_{j}^{t} y_{j}^{t}+\sum_{i \in I} \sum_{j \in J} \sum_{m \in M} \sum_{p \in P} a_{i}^{p} x_{i j}^{m p}+\sum_{i \in J \cup K} \sum_{t \in T} \sum_{p \in P} e_{i}^{p t} h_{i}^{p t}+ \\
\sum_{(i, j) \in A} \sum_{m \in M} g_{i j}^{m} u_{i j}^{m}+\sum_{(i, j) \in A} \sum_{m \in M} \sum_{p \in P} v_{i j}^{m p} x_{i j}^{m p} .
\end{array}
$$

The environmental objective (2) consists of three terms representing the $\mathrm{CO}_{2}$ emissions due to purchasing and supplying of products from suppliers to plants, the $\mathrm{CO}_{2}$ emissions at plants and $\mathrm{DC}$, and the $\mathrm{CO}_{2}$ emissions arising from transportation modes, respectively.

$$
\begin{array}{r}
\min z_{2}=\sum_{i \in I} \sum_{j \in J} \sum_{m \in M} \sum_{p \in P} b_{i}^{p} x_{i j}^{m p}+ \\
\sum_{i \in J \cup K} \sum_{t \in T} \sum_{p \in P} q_{i}^{p t} h_{i}^{p t}+ \\
\sum_{(i, j) \in A} \sum_{m \in M} r_{i j}^{m p} x_{i j}^{m p} .
\end{array}
$$

Constraints (3) are the flow conservation constraints through the network. 


$$
\sum_{i \in V} \sum_{m \in M} x_{i j}^{m p}=\sum_{k \in V} \sum_{m \in M} x_{j k}^{m p} \quad \forall j \in J \cup K, p \in P .
$$

Constraints (4) and (5) calculate the amount of product entering in each facility.

$$
\begin{array}{rlrl}
\sum_{t \in T} h_{j}^{t p} & =\sum_{i \in I} \sum_{m \in M} x_{i j}^{m p} & \forall j \in J, p \in P \\
\sum_{t \in T} h_{k}^{t p}=\sum_{j \in J} \sum_{m \in M} x_{j k}^{m p} & \forall k \in K, p \in P .
\end{array}
$$

Constraints (6) ensure the satisfaction of customers demands.

$$
\sum_{k \in K} \sum_{m \in M} x_{k l}^{m p} \geq d_{l}^{p} \quad \forall l \in L, p \in P
$$

Constraints (7) and (8) force the model to satisfy capacity constraint at suppliers, plants and DCs respectively. In addition, constraints (8) state that the products can be shipped only to open facilities.

$$
\begin{array}{ll}
\sum_{j \in J} \sum_{m \in M} \sum_{p \in P} x_{i j}^{m p} \leq \operatorname{cap}_{i} & \forall i \in I \\
\sum_{p \in P} h_{i}^{t p} \leq \operatorname{cap}_{i} y_{i}^{t} & \forall j \in J \cup K, t \in T
\end{array}
$$

140 Constraints (9) ensure that at most one technology level is selected for each facility.

$$
\sum_{t \in T} y_{j}^{t} \leq 1 \quad \forall j \in J \cup K
$$

Constraints (10) ensure that at most one transportation mode is selected between two 
connected nodes. Constraints (11) - (12) guarantee that the volume limitation of each given mode is satisfied.

$$
\begin{array}{ll}
\sum_{m \in M} u_{i j}^{m} \leq 1 & \forall(i, j) \in A \\
\sum_{p \in P} x_{i j}^{m p} \leq \bar{V}_{i j}^{m} u_{i j}^{m} & \forall(i, j) \in A, m \in M \\
\sum_{p \in P} x_{i j}^{m p} \geq \underline{V}_{i j}^{m} u_{i j}^{m} & \forall(i, j) \in A, m \in M .
\end{array}
$$

Without loss of generality, we also consider possible restrictions on the number of open facilities. Decision makers or industrial experts are often able to a priori determine reasonably narrow ranges, denoted by $\left\{J_{\min }, \ldots, J_{\max }\right\}$ and $\left\{K_{\min }, \ldots, K_{\max }\right\}$, respectively, for the number of plants and DCs to be selected. Constraints (13)-(14) bound the number of open plants and DCs respectively. These constraints can be discarded by setting minimal values at 0 and maximal values at $+\infty$.

$$
\begin{aligned}
& J_{\text {min }} \leq \sum_{j \in J} \sum_{t \in T} y_{j}^{t} \leq J_{\max } \\
& K_{\text {min }} \leq \sum_{k \in K} \sum_{t \in T} y_{k}^{t} \leq K_{\text {max }} .
\end{aligned}
$$

Constraints (15) - (18) state binary and non-negativity restrictions on decision variables.

$$
\begin{array}{ll}
y_{j}^{t} \in\{0,1\} & \forall j \in J \cup K, t \in T \\
u_{i j}^{m}=\{0,1\} & \forall(i, j) \in A, m \in M \\
x_{i j}^{m p} \geq 0 & \forall(i, j) \in A, p \in P, m \in M \\
h_{i}^{p t} \geq 0 & \forall i \in J \cup K, p \in P, t \in T .
\end{array}
$$




\section{Multi Directional Local Search (MDLS)}

In this section, we introduce the MDLS metaheuristic for solving the bi-objective SCND model (1)-(18). Section 3.1 presents the main scheme of our implementation of the MDLS algorithm. The local search algorithm used within the MDLS framework is presented in Section 3.2. Subsequent sections detail the key steps of this algorithm. Finally, following the ideas of Lian et al. (2016), Section 3.5 introduces a refinement of MDLS that restricts the number of solutions in the non-dominated set and intensifies the search around the least crowded areas.

\subsection{The Multi-Directional Local Search algorithm for bi-objective SCND}

The Algorithm 1 describes our implementation of the MDLS framework.

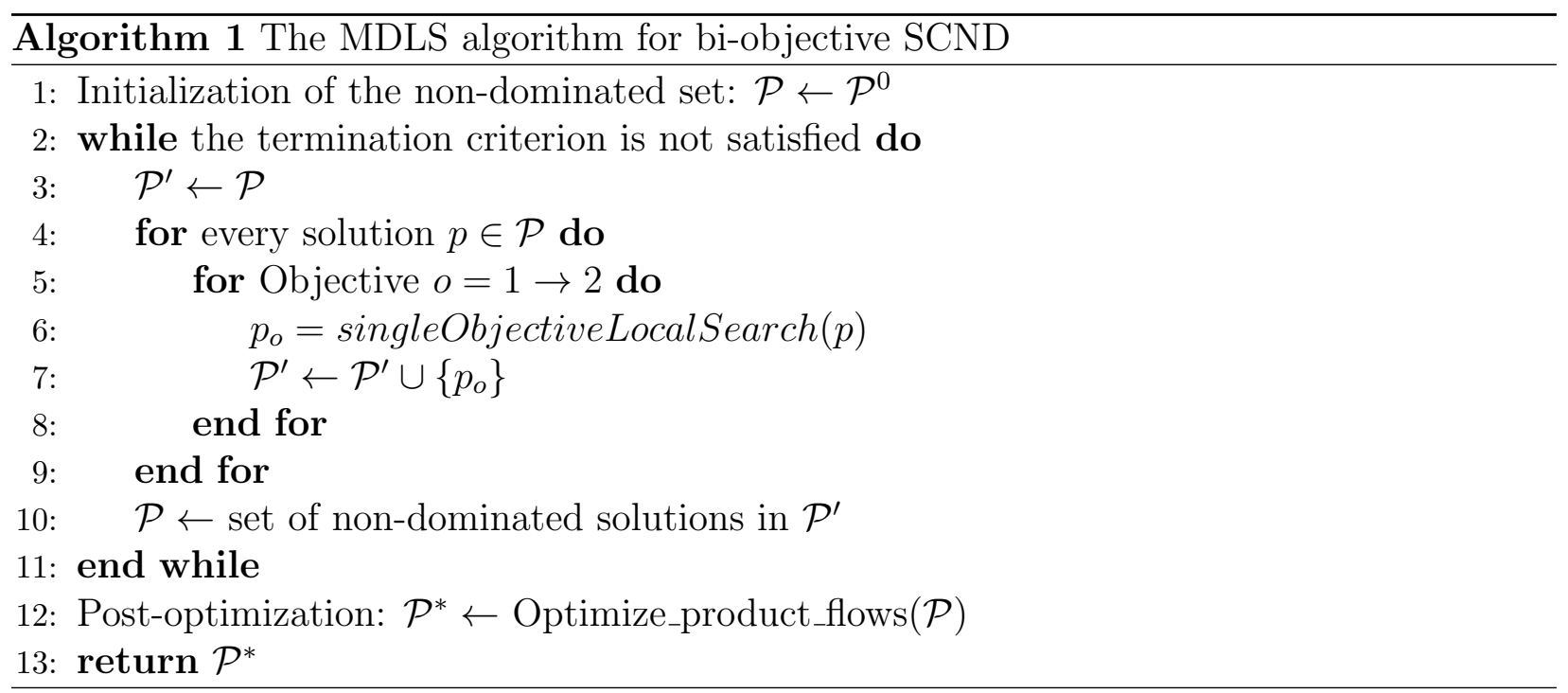

The algorithm is initialized with an initial non-dominated set (see section 3.3). At every iteration, all solutions of the current non-dominated set are modified by running independent local searches (see section 3.2) with respect to each objective (cost and $\mathrm{CO}_{2}$ emissions). In original MDLS developed by Tricoire (2012), the local search is applied only to one randomly 
selected solution. Applying the LNS on all solutions $p \in \mathcal{P}$ in both directions yields a new

165

set $\mathcal{P}^{\prime}$ of solutions. Since $\mathcal{P}^{\prime}$ may contain dominated solutions, the non-dominated set $\mathcal{P}$ at next iteration is built by removing all dominated solutions in $\mathcal{P}^{\prime}$ (line 10). In line 12 , a post-optimization step slightly improves the value of all continuous variables (see section $3.4)$.

\subsection{Single-objective local search}

The local search method used in Line 6 of Algorithm 1 is the Large Neighborhood Search (LNS) metaheuristic (Pisinger and Ropke, 2010). The principle of the LNS is to iteratively destroy and repair the current solution in order to progressively improve it. A destroy method destructs part of the current solution while a repair method rebuilds the destroyed solution so that a new feasible solution is found (Shaw, 1998). Problem specific destroy and repair operators (methods) have to be designed in order to efficiently solve the optimization problem considered. In this paper, we reuse the Large Neighborhood Search algorithm extensively described in Eskandarpour et al. (2017). In practice, any other single-objective local search method can be used instead. This LNS algorithm sets facility location decisions associated with plants and DCs. Transportation modes and product flow decisions are determined by a greedy heuristic consisting of assigning product flows to the nearest facility, via the cheapest transportation mode. The LNS algorithm embeds 6 destroy operators, 9 repair operators, and 2 combined (destroy + repair) operators. The determination of technology levels uses a biased roulette wheel giving much higher probability to the technologies with lower fixed costs (resp. $\mathrm{CO}_{2}$ emissions). This approach helps diversify the search.

\subsection{Initial non-dominated set}

The initial non-dominated set $\mathcal{P}^{0}$ must contain mutually non-dominated solutions that preferably represents good diversity of solutions with respect with both objectives. This diversity will help MDLS explore various areas of the solution space. Let $n j=\sum_{j \in J} \sum_{t \in T} y_{j}^{t}$ 
and $n k=\sum_{k \in K} \sum_{t \in T} y_{k}^{t}$ represent the number of production facilities and DCs in a soludistance correspond to isolated solutions. In a bi-objective context, the crowding distance of a particular solution is simply obtained by calculating the average distances between this 


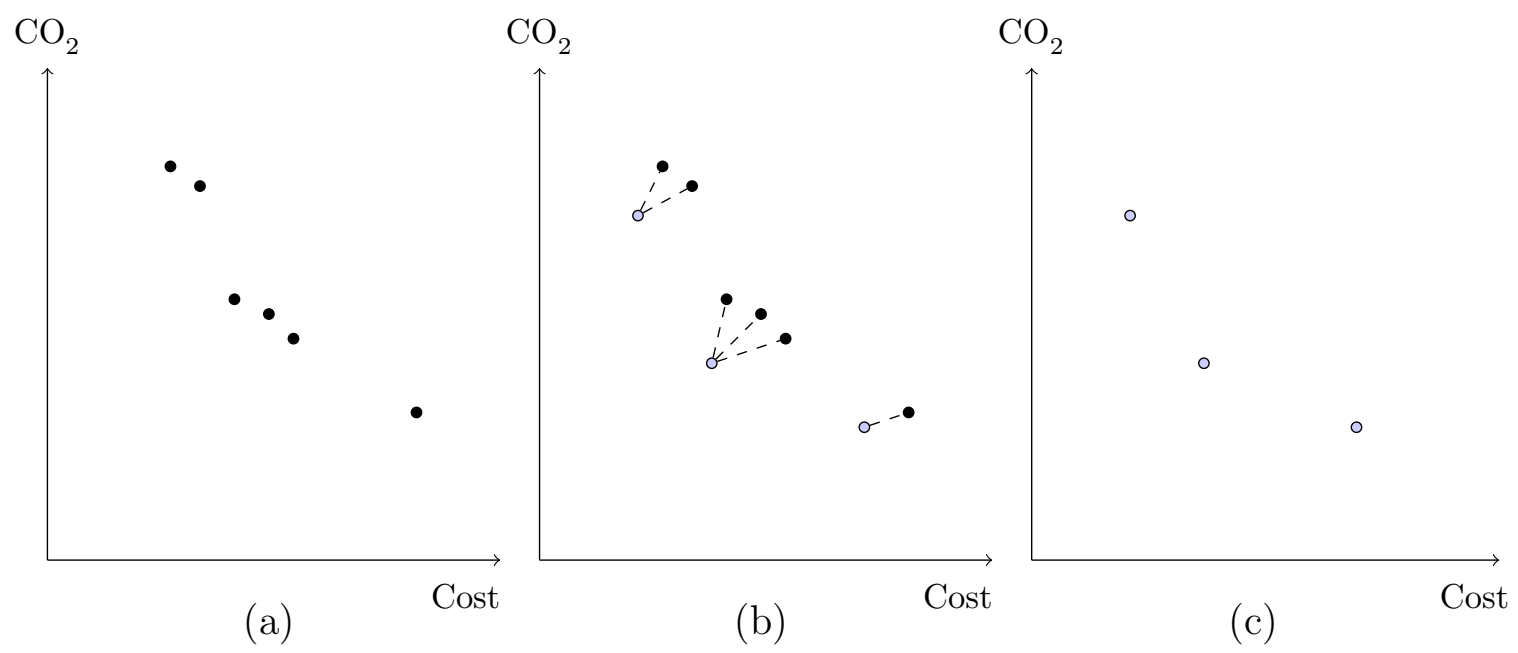

Figure 1: Post-optimization. (a) non-dominated set before post-optimization (b) Neighbors obtained by post-optimization. (c) Final non-dominated set.

solution and its two neighboring solutions along each of the objectives in the non-dominated set ( i.e. the solutions that are just better than and just worse than it for both of the objectives) (Deb et al., 2002). This calculation takes place at every iteration of the main loop in Algorithm 1. Then, solutions are sorted in non-increasing order of their crowding distances and the first $P_{\max }$ solutions only are conserved. Note that the crowding distance of the two extremal solutions in the non-dominated set are artificially set to $+\infty$, so that they are kept in any case.

We implemented the IMLDS algorithm and added an intensification step. In IMDLS, local search is applied on each solution of the non-dominated set. Exactly one local search is performed from each non-dominated solution. (Caballero et al., 2007) formulated the intuitive idea that there is always a possibility that another non-dominated solution is still to be discovered around a non-dominated solution. The intensification process is based on the assumption that these "still to be discovered non-dominated solutions" are more likely to be found near the least crowded areas of the set $\mathcal{P}$. Hence, a small subset of $\tau<P_{\max }$ 
solutions with highest crowding distances is selected. From these points, we perform several local searches (instead of one) and consider all solutions generated. This is illustrated by Example 1. Note that this intensification step makes sense only if the local search contains some stochastic components, so that distinct solutions are returned by successive calls.

Example 1. Consider 5 solutions denoted $A, B, C D$ and $E$ respectively, and assume $P_{\max }=$ 10 and $\tau=2$. Assume also that $B$ and $D$ have the largest crowding distances (Figure $2(a))$.

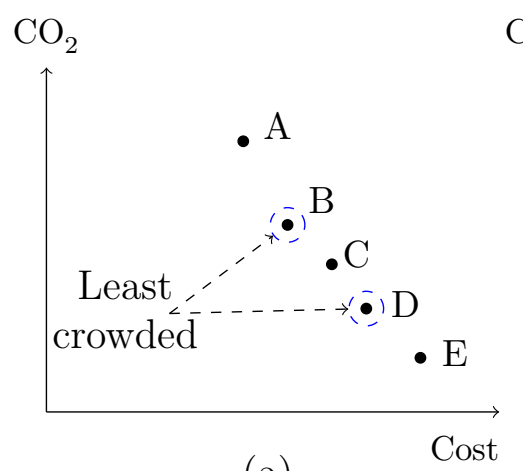

(a)

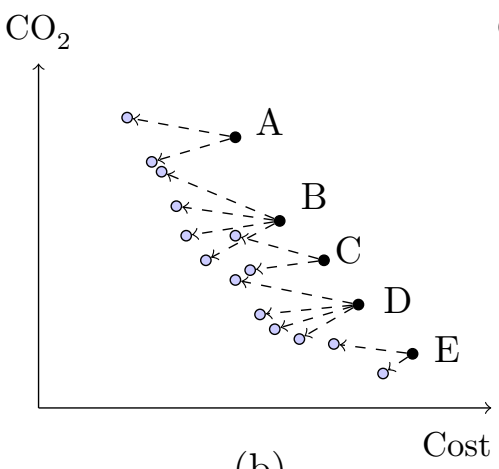

(b)

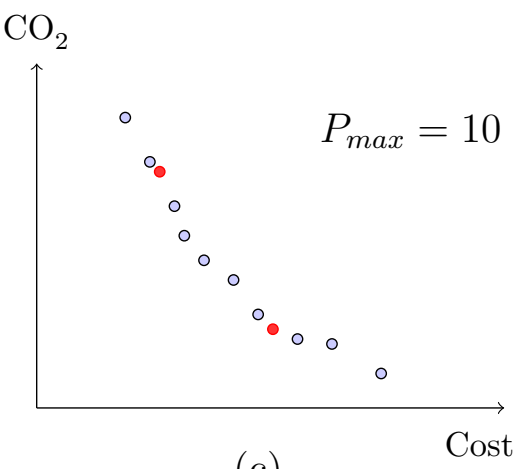

(c)

Figure 2: One MDLS iteration. (a) Starting set of solutions. (b) Neighbors obtained by MDLS around each solution. (c) Final non-dominated set.

Figure 2(b) shows 14 neighboring solutions obtained by applying one local search related to each objective starting from $A, C$ and $E$, and two local searches related to each objective starting from $B$ and D. Figure 2(c) presents the set of 12 mutually non-dominated solutions among these 14 solutions. Since $P_{\max }=10$, the solutions displayed in red are removed from the current set.

\section{Computational experiments}

We evaluate our MDLS implementation through a comparison with the results obtained with the classical $\varepsilon$-constraint method (denoted thereafter by EC) and with the IMDLS 
framework proposed by Lian et al. (2016). All algorithms were coded in $\mathrm{C}++$ and run on a computer with four Intel 3.0 GHz CPUs and $8 \mathrm{~GB}$ of RAM.

The numerical experiments rely on a set of generated instances that are detailed in Section portation. Subsections 4.1.1 and 4.1.2 detail both cases.

\subsubsection{Cost and emissions related to facilities}

Technology levels installed in facilities influences the amount of $\mathrm{CO}_{2}$ emissions as well as fixed costs and processing costs. We considered two potential technologies levels $l_{1}$ (lowest) suppliers and facilities are modeled with a conversion factor $\varphi$ randomly generated in the 
Table 5: Test instances

\begin{tabular}{ccccccc}
\hline \multicolumn{1}{c}{$\mid$} & $|I|$ & $|J|$ & $|K|$ & $|L|$ & $J_{\max }$ & $K_{\max }$ \\
\hline Instance & & & & & & 6 \\
T1 & 6 & 6 & 12 & 60 & 3 & 7 \\
T2 & 7 & 7 & 14 & 70 & 4 & 8 \\
T3 & 8 & 8 & 16 & 80 & 4 & 9 \\
T4 & 9 & 9 & 18 & 90 & 5 & 10 \\
T5 & 10 & 10 & 20 & 100 & 5 & 12 \\
T6 & 12 & 12 & 24 & 120 & 6 & 14 \\
T7 & 14 & 14 & 28 & 140 & 7 & 16 \\
T8 & 16 & 16 & 32 & 160 & 8 & 18 \\
T9 & 18 & 18 & 36 & 180 & 9 & 10 \\
T10 & 20 & 20 & 40 & 200 & 10 & 20 \\
\hline T11 & 22 & 22 & 44 & 220 & 11 & 22 \\
T12 & 24 & 24 & 48 & 240 & 12 & 24 \\
T13 & 26 & 26 & 52 & 260 & 13 & 26 \\
T14 & 28 & 28 & 56 & 280 & 14 & 28 \\
T15 & 30 & 30 & 60 & 300 & 15 & 30 \\
\hline
\end{tabular}

interval $[2.5,4.5]$ (unit: $\mathrm{kg} \mathrm{CO}_{2}$ equiv./ton of product) for each type of product. As indicated by Table 6, we assume that the highest technology results in higher fixed cost but lower processing cost and $\mathrm{CO}_{2}$ emissions.

Table 6: Features of technology levels

\begin{tabular}{ccc}
\hline Technology level & $l_{1}$ & $l_{2}$ \\
\hline Fixed cost & $=$ & $+20 \%$ \\
Processing cost & $=$ & $-10 \%$ \\
Processing emission & $=$ & $-20 \%$ \\
\hline
\end{tabular}

\subsubsection{Cost and emissions related to transportation}

We assumed three transportation modes in the network. Each mode includes fixed cost and variable costs as well as $\mathrm{CO}_{2}$ emissions. Without loss of generality, mode 1 could be an internal fleet of trucks. Fixed cost of mode 1 was assumed to be 10000 . Mode 2 could represent an outsourced fleet of trucks (3PL) for the delivery of goods to customers. Variable 
275 they generally operate with higher truck fill rate and less empty truck repositionning, which improves their environmental efficiency. Mode 3 could correspond to inland navigation or rail transportation, for which fixed cost is assumed to be null and variable cost $80 \%$ of that of mode 1 .

In the context of supply chain network design, we consider quantities carried over long time periods (e.g. one year), by a fleet of vehicles. The loads carried vary from one trip to another, as well as the drivers and the traffic conditions. Thus, strategic models use averaged values of speed, load and traffic conditions for each trip. Under this assumption, transportation costs and emissions are considered roughly proportional to the distance traveled. We use conversion factors for half and full truckload, provided by the French Environment and Energy Management Agency (ADEME). According to Tables 32 and 35 by ADEME (2010), we consider conversion factors of 0.065 and $0.055 \mathrm{~kg}$ per km.ton for full and half truckload respectively, as well as $0.006 \mathrm{~kg}$ per km.ton mode 3. Finally, overall emissions on each arc are calculated by multiplying the arc length by the conversion factor and the amount of products shipped. ${ }^{1}$.

\subsection{The $\varepsilon$-constraint method and performance measures}

4.2.1. Results with the $\varepsilon$-constraint method (EC)

The main principle of EC is to convert a bi-objective model with two objectives $z_{1}$ and $z_{2}$ to a model with single objective $z_{1}$ and the constraint $z_{2} \leq \varepsilon$. Each value of the parameter $\varepsilon$ gives rise to a distinct MILP, which can be solved by any MILP solver or solution method. We used IBM Ilog Cplex 12.6 concert technology (standard tuning) with a time limit of 3 hours for each value of $\varepsilon$.

\footnotetext{
${ }^{1}$ A file detailing the generation of environmental factors along with test instances are accessible at https://data.mendeley.com/datasets/b2t84kg4wh/draft
} 
In our experiments, the value of $\varepsilon$ varies between the minimum and maximal levels of the

300

Table 7: Results with the $\varepsilon$-constraint method

\begin{tabular}{lllll}
\hline & $\begin{array}{l}\text { Size of non- } \\
\text { dominated set }\end{array}$ & $\begin{array}{l}\text { Total time } \\
\text { (in seconds) }\end{array}$ & $\begin{array}{l}\text { Sub-optimal } \\
\text { solutions }\end{array}$ & $\begin{array}{l}\text { Gap } \\
\text { (in \%) }\end{array}$ \\
\hline T1 & 10 & 757 & 0 & 0 \\
T2 & 10 & 9268 & 0 & 0 \\
T3 & 10 & 12916 & 0 & 0 \\
T4 & 10 & 23621 & 0 & 0 \\
T5 & 10 & 34713 & 1 & 0.07 \\
\hline T6 & 9 & 58866 & 2 & 0.35 \\
T7 & 10 & 79168 & 4 & 2.49 \\
T8 & 10 & $30 \mathrm{~h}$ & 10 & 5.82 \\
T9 & 9 & $30 \mathrm{~h}$ & 10 & 5.06 \\
T10 & 10 & $30 \mathrm{~h}$ & 10 & 4.09 \\
\hline T11 & 10 & $30 \mathrm{~h}$ & 10 & 3.01 \\
T12 & 9 & $30 \mathrm{~h}$ & 10 & 6.54 \\
T13 & 10 & $30 \mathrm{~h}$ & 10 & 5.59 \\
T14 & 10 & $30 \mathrm{~h}$ & 10 & 3.26 \\
T15 & 9 & $30 \mathrm{~h}$ & 10 & 5.75 \\
\hline
\end{tabular}


Table 7 shows the practical limits of the MILP solver. Small instances can be solved to optimality, at the price of high computational time. Solving realistic size instances requires using heuristic or meta-heuristic algorithms.

\subsubsection{Performance measures}

In this section, we compare the quality of the solutions obtained with MDLS with those obtained by EC. We used three classic performance measures: the hypervolume, the unary $\epsilon$ indicator and the ratio of Pareto optimal solutions.

Each measure partially reflects the performance of non-dominated set. Since all measures have some drawbacks, using several measures at the same time can help fairly comparing several fronts (Tricoire, 2012).

- The hypervolume measure $H$ (Zitzler et al., 2003) represents the surface covered by a set of non-dominated solutions with respect to a reference point (here the Nadir Point). Thus, larger hypervolume measure indicates better quality of the non-dominated set.

- The unary $\epsilon$ indicator (Zitzler et al., 2003) is defined as the smallest multiplicative coefficient to apply to an approximate set so as to completely dominate the reference set. It smallest value is 1 and smaller values are better.

- The ratio of Pareto optimal solutions ( $R$ ) (Altiparmak et al., 2006): given solutions sets $S_{1}$ and $S_{2}$ obtained by two methods, this ratio shows the percentage of solutions from set $S_{1}$ not dominated by any member of set $S_{1} \cup S_{2}$. The higher this ratio is, the better the solution set.

\subsection{Parameter Settings}

The parameters of MDLS have been determined based on preliminary computational experiments, with the goal of keeping good trade-off between the solution quality and computational time. The MDLS algorithm is stopped after 15000 iterations. The value of parameter 
$\tau$ has been set to 2 and local searched are applied 5 times on each of the $\tau$ solutions. The maximum size of the non-dominated set has been set to $P_{\max }=10$.

\subsection{Evaluating components of Algorithm 1}

Table 8 shows the contribution of three important components of Algorithm 1: initialization (line 1), the main MDLS loop (lines 2-1) and post-optimization (line 12).

Table 8: Contribution of each phase of the algorithm

\begin{tabular}{|c|c|c|c|c|c|c|c|c|}
\hline \multirow[b]{2}{*}{ Instance } & \multicolumn{2}{|c|}{ Initialization } & \multicolumn{3}{|c|}{ Main loop } & \multicolumn{3}{|c|}{ Post-optimization } \\
\hline & \# sol & CPU (s) & \# sol & Ratio & CPU (s) & \# sol & Ratio & $\mathrm{CPU}(\mathrm{s})$ \\
\hline$T 1$ & 5.2 & 1 & 6.4 & 1 & 1127 & 5 & 1 & 1 \\
\hline$T 2$ & 6.0 & 2 & 5.4 & 1 & 1577 & 4.6 & 1 & 2 \\
\hline T3 & 6.4 & 2 & 5.6 & 0.83 & 1926 & 5.2 & 1 & 1 \\
\hline$T 4$ & 8.0 & 2 & 7.2 & 1 & 2815 & 4.8 & 1 & 1 \\
\hline T5 & 5.8 & 3 & 6.6 & 0.67 & 3093 & 5.8 & 1 & 1 \\
\hline T6 & 9.4 & 9 & 5.4 & 1 & 4400 & 5 & 1 & 7 \\
\hline$T 7$ & 9.0 & 18 & 9.8 & 1 & 6596 & 8.8 & 0.9 & 9 \\
\hline$T 8$ & 8.8 & 41 & 5.6 & 1 & 8059 & 5.4 & 1 & 26 \\
\hline T9 & 7.4 & 45 & 9.2 & 1 & 9403 & 9.2 & 1 & 16 \\
\hline T10 & 8.2 & 79 & 9.6 & 0.82 & 12277 & 9.2 & 1 & 31 \\
\hline$T 11$ & 9.2 & 98 & 7.6 & 0.80 & 14872 & 7.6 & 1 & 70 \\
\hline T12 & 7.2 & 178 & 7.8 & 1 & 17998 & 5.4 & 1 & 89 \\
\hline T13 & 10.0 & 288 & 7.6 & 1 & 21712 & 7.6 & 1 & 201 \\
\hline T14 & 9.4 & 456 & 9.2 & 1 & 26558 & 9.2 & 1 & 302 \\
\hline T15 & 9.8 & 532 & 8.6 & 0.83 & 30871 & 8 & 1 & 418 \\
\hline Average & 8.0 & 117 & 7.4 & 0.93 & 10885 & 6.7 & 0.99 & 78 \\
\hline
\end{tabular}

The MDLS was run 5 times on each instance. Columns 2, 4 and 7 report the average number of solutions (\# sol) in the non-dominated set. Columns 3,6 and 9 indicate the running time (in seconds). As stated earlier, the number of non-dominated solutions is slightly decreased by the post-optimization step, since calculating optimal product flows enables merging some neighboring non-dominated solutions. Regarding computing times, the initialization and the post-optimization require less than $2 \%$ of the total time. Columns 5 and 8 report the ratio of Pareto optimal solutions associated with the MDLS iterations and the post-optimization steps. The average values of 0.93 and 0.99 ) indicate that each component of the algorithm significantly improves the results of the preceding one. 
One main difference between MDLS proposed in this study and in Lian et al. (2016) with the original one in Tricoire (2012) is to provide a non-dominated set with a small set of solutions. Providing a reasonable number of representative solutions to decision makers might be more desirable (Govindan et al., 2015). We also show that this speeds up the convergence to the Pareto set. We run MDLS with either $P_{\max }=10$ or $P_{\max }=+\infty$, with a time limit of 10 hours. The results presented in Table 9 show the superiority of the MDLS with $P_{\max }=10$ (denoted MDLS (10)) over the one with unlimited non-dominated set (denoted MDLS ( $\infty)$ ).

Table 9: Impact of the non-dominated set limitation

\begin{tabular}{lccccc}
\hline & \multicolumn{2}{c}{ \# sol } & & \multicolumn{2}{c}{$R$} \\
\cline { 2 - 3 } \cline { 5 - 6 } Instance & MDLS $(10)$ & MDLS $(\infty)$ & & MDLS $(10)$ & MDLS $(\infty)$ \\
\hline T1 & 5 & 34 & & 1 & 0.79 \\
T2 & 5 & 72 & & 1 & 0.60 \\
T3 & 7 & 48 & & 1 & 0.73 \\
T4 & 4 & 62 & & 1 & 0.48 \\
T5 & 7 & 53 & & 1 & 0.42 \\
\hline T6 & 6 & 57 & & 1 & 0.09 \\
T7 & 10 & 86 & & 1 & 0.55 \\
T8 & 5 & 57 & & 1 & 0.53 \\
T9 & 9 & 51 & & 1 & 0.20 \\
T10 & 10 & 89 & & 1 & 0.47 \\
\hline T11 & 5 & 54 & & 1 & 0.94 \\
T12 & 6 & 58 & & 1 & 0.52 \\
T13 & 7 & 87 & & 1 & 0.46 \\
T14 & 10 & 56 & & 1 & 0.45 \\
T15 & 6 & 88 & & 1 & 0.47 \\
\hline average & 6.8 & 63.5 & &
\end{tabular}

Columns 2 and 3 show the size of the non-dominated set obtained with both variants. Columns 4 and represent the ratio of Pareto optimal solutions corresponding to MDLS(10) and $\operatorname{MDLS}(\infty)$. Limiting the set of solutions acts as an intensification of the algorithm.

Unlike the IMDLS, our approach aggressively explores the solution space around the least crowded areas. Table 10 compares the result of one single run of our MDLS implementation 
and IMDLS in terms of number of non-dominated solutions, ratio and CPU time.

Table 10: Comparison between MDLS and IMDLS

\begin{tabular}{|c|c|c|c|c|c|c|}
\hline \multirow[b]{2}{*}{ Instance } & \multicolumn{2}{|c|}{ \# sol } & \multicolumn{2}{|c|}{$R$} & \multicolumn{2}{|c|}{$\mathrm{CPU}(\mathrm{s})$} \\
\hline & $M D L S$ & $I M D L S$ & $M D L S$ & $I M D L S$ & $M D L S$ & $I M D L S$ \\
\hline$T 1$ & 5 & 7 & 0.61 & 0.68 & 1083 & 1061 \\
\hline$T 2$ & 5 & 5 & 0.62 & 0.75 & 1517 & 1396 \\
\hline T3 & 7 & 9 & 0.71 & 0.67 & 1871 & 1759 \\
\hline$T 4$ & 4 & 4 & 0.61 & 0.49 & 2733 & 2433 \\
\hline T5 & 7 & 5 & 0.8 & 0.75 & 2911 & 2852 \\
\hline T6 & 6 & 8 & 0.62 & 0.78 & 4063 & 3982 \\
\hline T7 & 10 & 5 & 0.63 & 0.8 & 6821 & 6480 \\
\hline T8 & 5 & 5 & 0.84 & 0.7 & 8207 & 7304 \\
\hline T9 & 9 & 7 & 0.71 & 0.74 & 9274 & 8440 \\
\hline T10 & 10 & 10 & 0.72 & 0.62 & 12511 & 11260 \\
\hline T11 & 5 & 5 & 0.71 & 0.69 & 15491 & 15181 \\
\hline T12 & 6 & 8 & 0.64 & 0.48 & 18082 & 16997 \\
\hline T13 & 7 & 4 & 0.77 & 0.64 & 22645 & 20834 \\
\hline T14 & 10 & 6 & 0.83 & 0.67 & 28409 & 25568 \\
\hline T15 & 6 & 9 & 0.76 & 0.63 & 32776 & 31792 \\
\hline Average & 6.80 & 6.47 & 0.71 & 0.67 & 11226 & 10489 \\
\hline
\end{tabular}

The overall results do not show significant difference between both approaches. However, as the instances size grow, the performance of MDLS tends to improve. For instance, the average ratio $R$ of MDLS and IMDLS for instances T11 to T15 are 0.74 and 0.62 respectively.

\subsection{Computational results}

To compare the non-dominated set found by MDLS and EC, we ran both methods 5 times with 10 different values of $\varepsilon$ and a time limit of 3 hours for each value of $\varepsilon$. The solutions provided by EC are Pareto optimal when the corresponding MILPs are solved to optimality. Hence, some solutions obtained with the MDLS may dominate those obtained by EC.

Table 11 reports the three performance measures described above. Columns 2 and 3 show the average ratio $(R)$ for each method. Columns 4 and 5 show the value of unary $\epsilon$ indicators. Column 6 shows the gap between the hypervolume value of MDLS and EC. To 
measure the ratio $R$ and the unary $\epsilon$ indicator, the non-dominated sets are compared with a common reference set, which consists of the set of all non-dominated solutions provided by these methods.

Table 11: Comparison between MDLS and EC

\begin{tabular}{|c|c|c|c|c|c|}
\hline \multirow[b]{2}{*}{ Instance } & \multicolumn{2}{|c|}{$R$} & \multicolumn{2}{|c|}{ Unary $\epsilon$} & \multirow{2}{*}{$H \%$} \\
\hline & MDLS & $\mathrm{EC}$ & MDLS & EC & \\
\hline$T 1$ & 0.48 & 1 & 1.95 & 1.63 & -1.33 \\
\hline $\mathrm{T} 2$ & 0.64 & 1 & 1.84 & 1.63 & -0.81 \\
\hline T3 & 0.34 & 1 & 1.84 & 1.7 & -0.16 \\
\hline T4 & 0.21 & 1 & 1.51 & 1.41 & -0.49 \\
\hline T5 & 0.38 & 1 & 1.91 & 1.67 & -0.14 \\
\hline $\bar{A} \bar{v} \bar{e} \overline{a g} \bar{e}$ & $\overline{0} . \overline{4} \overline{1}$ & 1 & $\overline{1} \overline{1} \overline{1}$ & $\overline{1.6 \overline{1}}$ & $-\overline{0}-\overline{5} \overline{9}$ \\
\hline T6 & 0.32 & 1 & 1.8 & 1.62 & -0.34 \\
\hline$T 7$ & 0.34 & 0.85 & 1.3 & 1.66 & -0.26 \\
\hline$T 8$ & 0.46 & 0.8 & 1.58 & 1.73 & -0.64 \\
\hline T9 & 0.61 & 0.79 & 1.49 & 1.67 & 0.21 \\
\hline T10 & 0.67 & 0.73 & 1.36 & 1.63 & -0.22 \\
\hline $\bar{A} \overline{\text { verage }} \overline{\text { e }}$ & $\overline{0} . \overline{4} 8$ & $\overline{0} . \overline{8} \overline{3}$ & $1.5 \overline{0}$ & $\overline{1}-\overline{6}$ & $-0.2 \overline{5}$ \\
\hline T11 & 0.72 & 0.68 & 1.68 & 1.64 & 0.43 \\
\hline $\mathrm{T} 12$ & 0.66 & 0.7 & 1.43 & 1.83 & 0.75 \\
\hline$T 13$ & 0.81 & 0.7 & 1.37 & 1.59 & 0.64 \\
\hline T14 & 0.72 & 0.65 & 1.47 & 1.62 & 0.24 \\
\hline T15 & 0.69 & 0.72 & 1.63 & 1.72 & 0.41 \\
\hline $\bar{A} \overline{\text { verage }}$ & $\overline{0} . \overline{7} \overline{2}$ & $\overline{0} . \overline{6} \overline{9}$ & $\overline{1.5 \overline{1}}$ & $\overline{1.6 \overline{8}}$ & $\overline{0.4} \overline{9}$ \\
\hline $\begin{array}{l}\text { Overall } \\
\text { Average }\end{array}$ & 0.54 & 0.84 & 1.61 & 1.65 & -0.11 \\
\hline
\end{tabular}

By definition, a solution from the MDLS set is dominated in a one to one comparison with an optimal point provided by EC. Thus, the ratio $R$ associated with EC is much higher (0.84 against 0.54$)$. Nonetheless, as the size of instances increases, the ratio associated with MDLS tends to increase while the ratio associated with EC decreases.

MDLS has a slightly better average unary $\epsilon$ than the EC (1.61 versus 1.65). Especially for large datasets, MDLS has more ability to find several solutions that minimize the second objective, so that the tail of the EC front is dominated by MDLS. This is illustrated by 
Figure 3 representing instance T14. Eventually, the hypervolume indicator shows that MDLS when the instance size increases.

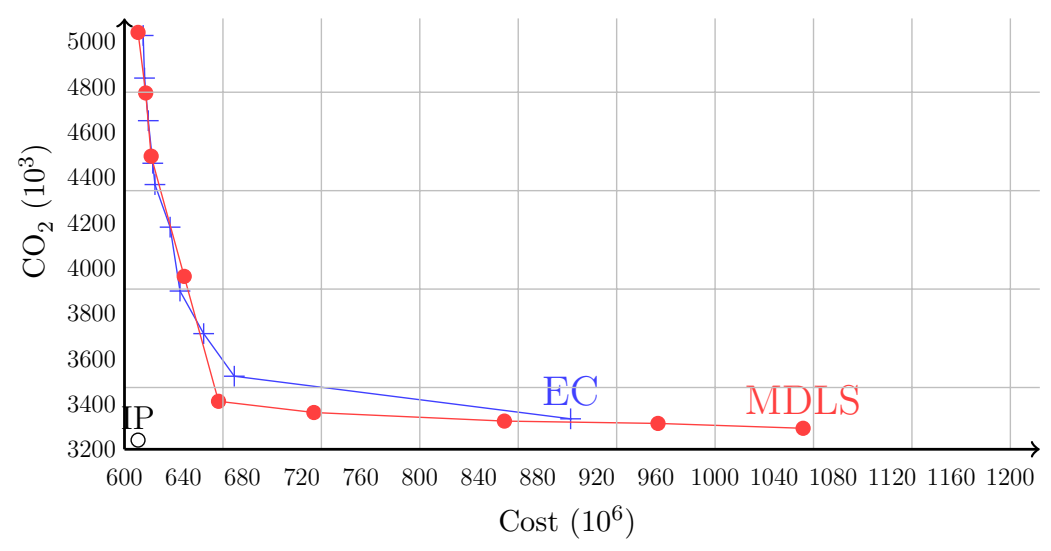

Figure 3: Comparison of the non-dominated sets for instance T14

\section{Managerial insights and conclusion}

Our experiments also showed that the supply chain topology can vary from one nondominated solution to another one. As an example, Figure 4 represents an non-dominated set obtained for instance T4 (with 9 suppliers, 9 potential plants, 18 potential DCs, and 90 customer).

The Figure 5 represents the selected plants and DCs corresponding to three particular solutions: solution A minimizing cost, a trade-off solution B and the greenest solution C, respectively. The technology levels used at each facility are represented with distinct colors.

Solutions A, B and C have completely different topologies. For example, there are 4 plants and 6 DCs in solution A, most of them having the lower technology level. Solution B is quite similar to solution A, the main difference comes from the improvement of technology levels. On the other side, cost is not a criterion in solution C. Thus all candidate facilities are open, with the highest technology level. This confirms the conclusion of Du and Evans (2008), who 


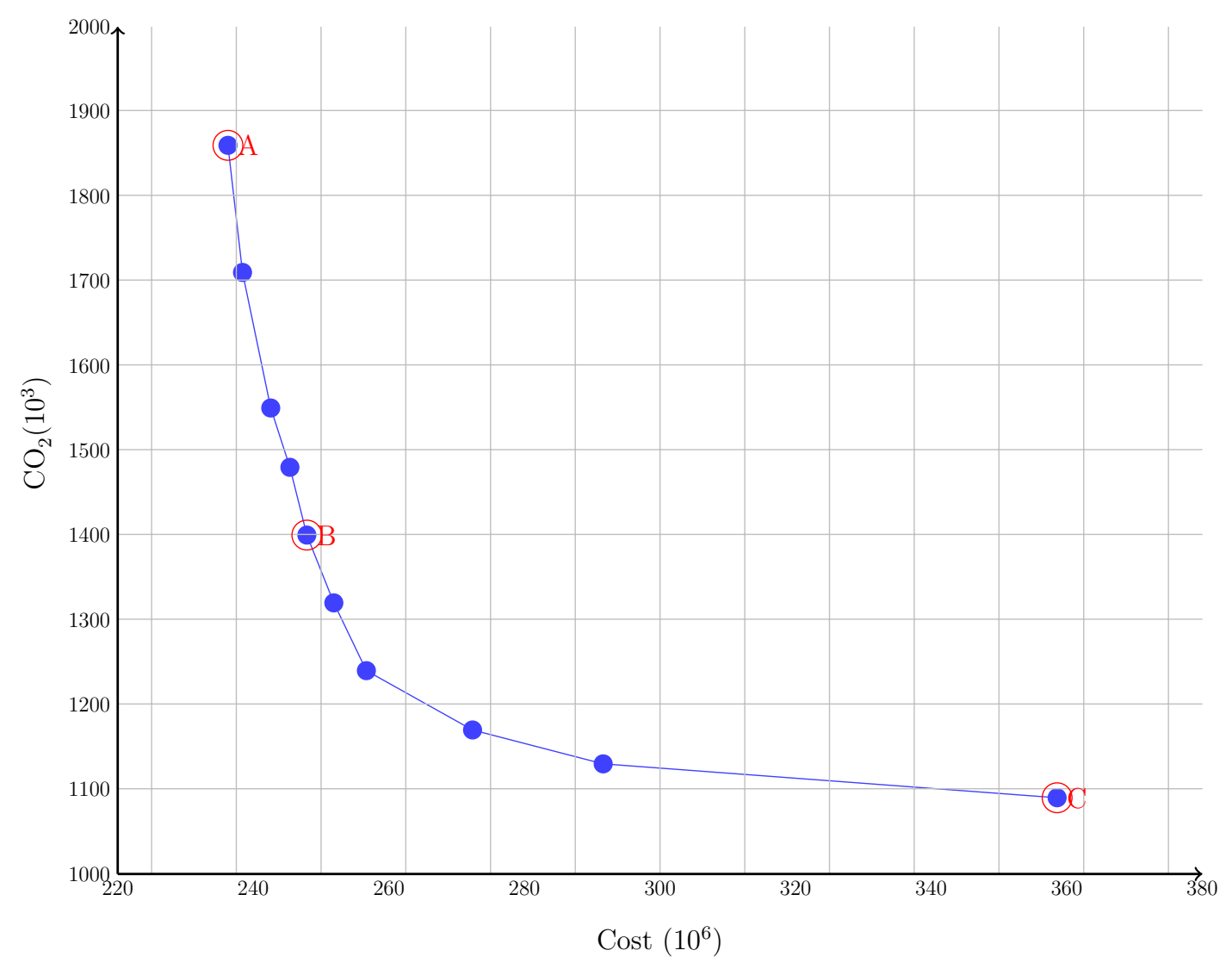

Figure 4: non-dominated set for instance T4

(A)

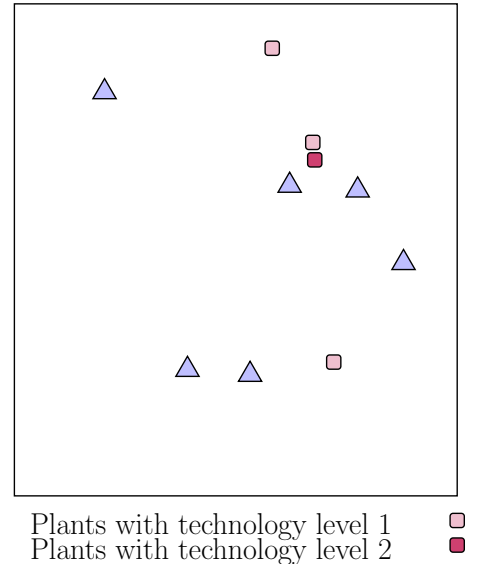

(B)

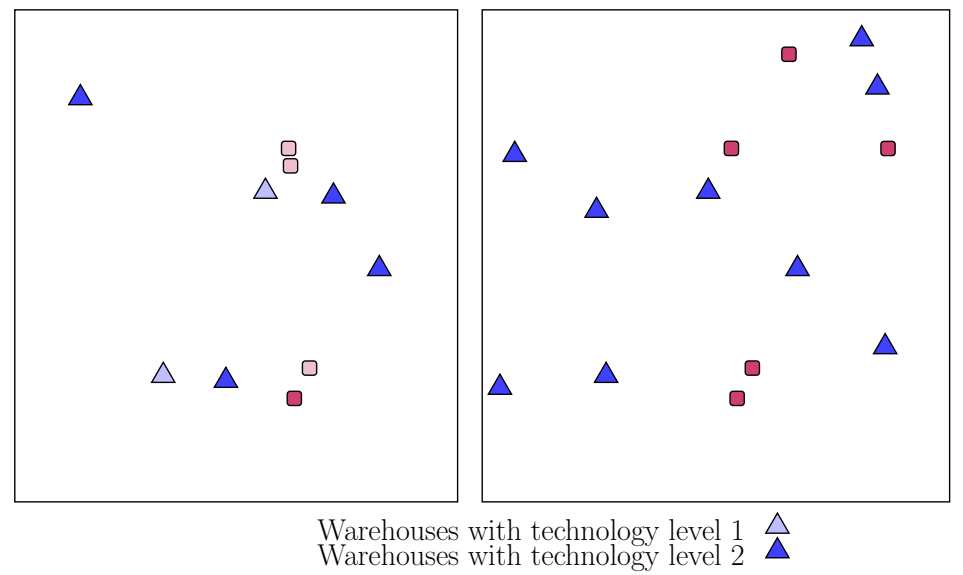

Figure 5: Supply chain topologies in solutions A to C 

search method for both objectives. We exploited the idea of crowding distance to better intensify the search as well as limiting the number of solutions in the non-dominated set.

Using three indicators, we compared the quality of solutions obtained with our MDLS 


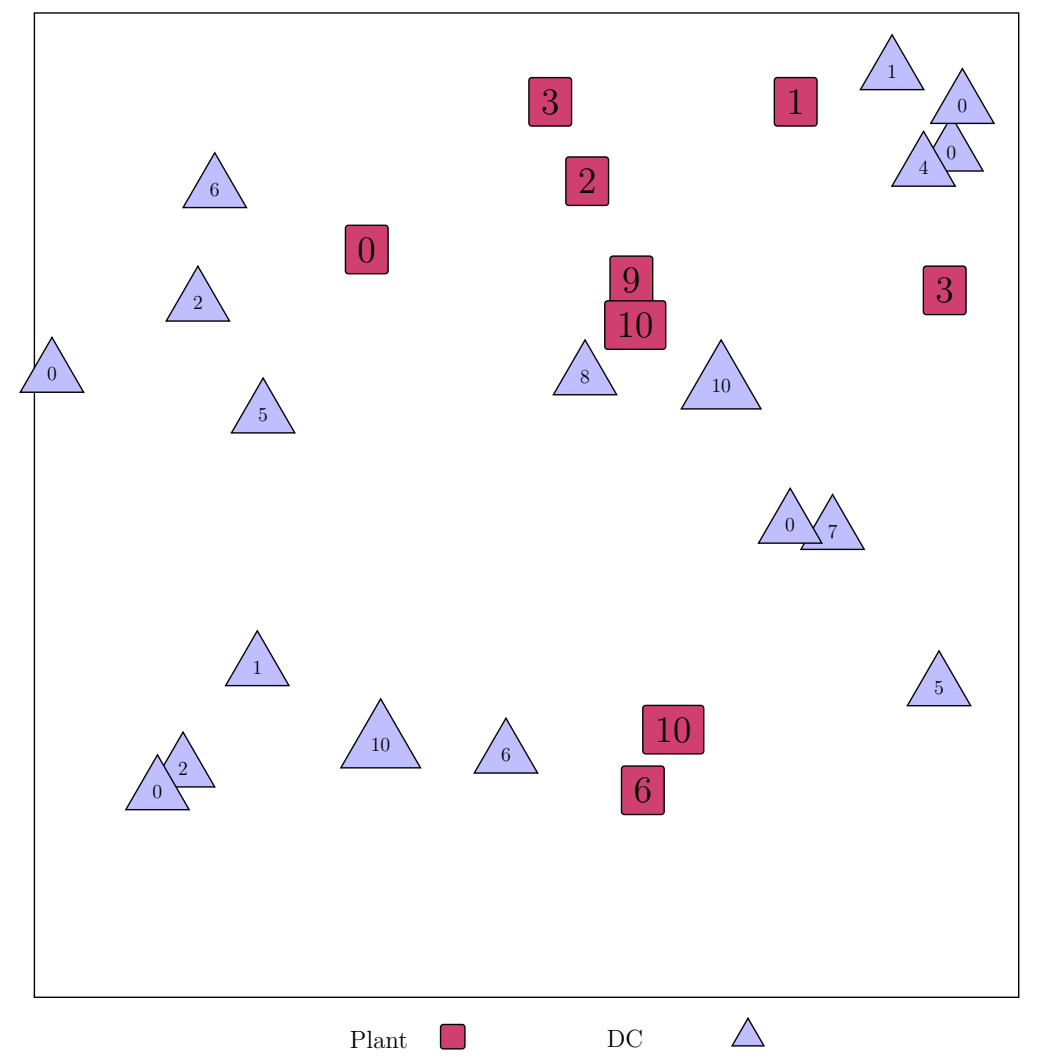

Figure 6: Number of occurences of each facility location in all non-dominated solutions 
425

procedure and those obtained with Cplex by solving the MILP model with the $\varepsilon$-constraint method. Our experiments show that the MDLS outperforms the $\varepsilon$-constraint method, and this outperformance becomes more obvious as the size of instances grows.

Sustainable SCND problems are complex in nature because they address the three dimensions of sustainable development. Our work could lead to many extensions and further researches for a more comprehensive handling of economic, environmental as well as quantifiable social criteria by extending the procedures to multiple dimensions. For example, one may investigate the impact of the incentives offered by governments to promote the use of cleaner technologies. Another promising research direction is to analyse the complex nature of emissions considering aspects such as nonlinear tax rates, multivariate emission functions and uncertainty (Waltho et al., 2019). The integration of social criteria such as the impact on employment or social life-cycle analysis would also lead to a challenging optimisation problem.

Acknowledgement: This research was supported partially by the Région Pays de la Loire through the research project OLASI, which has been labeled by the competitiveness clusters EMC2 and Nov@log. This support is gratefully acknowledged.

\section{References}

M. H. Alavidoost, M. Tarimoradi, and M. H. F. Zarandi. Bi-objective mixed-integer nonlinear programming for multi-commodity tri-echelon supply chain networks. Journal of Intelligent Manufacturing, 29(4):809-826, 2018.

Z. Alizadeh Afrouzy, M. M. Paydar, S. H. Nasseri, and I. Mahdavi. A meta-heuristic approach supported by NSGA-II for the design and plan of supply chain networks considering new product development. Journal of Industrial Engineering International, 14(1):95-109, 2018.

F. Altiparmak, M. Gen, L. Lin, and T. Paksoy. A genetic algorithm approach for multi- 
objective optimization of supply chain networks. Computers \& Industrial Engineering, 51 (1):196 - 215, 2006.

S. M. Arabzad, M. Ghorbani, and R. Tavakkoli-Moghaddam. An evolutionary algorithm for a new multi-objective location-inventory model in a distribution network with transportation modes and third-party logistics providers. International Journal of Production Research, 53(4):1038-1050, 2015.

R. Caballero, M. González, F. Guerrero, J. Molina, and C. Paralera. Solving a multiobjective location routing problem with a metaheuristic based on tabu search. application to a real case in Andalusia. European Journal of Operational Research, 177(3):1751 - 1763, 2007.

L. Canales-Bustos, E. Santibañez-González, and A. Candia-Véjar. A multi-objective optimization model for the design of an effective decarbonized supply chain in mining. International Journal of Production Economics, 193(Supplement C):449 - 464, 2017. ISSN 0925-5273.

Y. Cardona-Valdés, A. Álvarez, and J. Pacheco. Metaheuristic procedure for a bi-objective supply chain design problem with uncertainty. Transportation Research Part B: Methodological, 60(0):66 - 84, 2014.

J. Cordeau, F. Pasin, and M. Solomon. An integrated model for logistics network design. Annals of Operations Research, 144:59-82, 2006.

K. Deb, A. Pratap, S. Agarwal, and T. Meyarivan. A fast and elitist multiobjective genetic algorithm: NSGA-II. IEEE Transactions on Evolutionary Computation, 6(2):182-197, 2002.

C. Defryn and K. Sörensen. Multi-objective optimisation models for the travelling salesman 
problem with horizontal cooperation. European Journal of Operational Research, 267(3): $891-903,2018$.

F. Dehghanian and S. Mansour. Designing sustainable recovery network of end-of-life products using genetic algorithm. Resources, Conservation and Recycling, 53(10):559-570, 2009.

E. Demir, T. Bektaş, and G. Laporte. The bi-objective Pollution-Routing Problem. European Journal of Operational Research, 232(3):464-478, 2014.

N. Demirel, E. Özceylan, T. Paksoy, and H. Gökçen. A genetic algorithm approach for optimising a closed-loop supply chain network with crisp and fuzzy objectives. International Journal of Production Research, 52(12):3637-3664, 2014.

K. Devika, A. Jafarian, and V. Nourbakhsh. Designing a sustainable closed-loop supply chain network based on triple bottom line approach: A comparison of metaheuristics hybridization techniques. European Journal of Operational Research, 235(3):594-615, 2014.

M. Doble and A. K. Kruthiventi. Chapter 10 - conclusions and future trends. In M. Doble and A. K. Kruthiventi, editors, Green Chemistry and Engineering, pages 297 - 312. Academic Press, Burlington, 2007.

F. Du and G. Evans. A bi-objective reverse logistics network analysis for post-sale service. Computers \& Operations Research, 35(8):2617 - 2634, 2008.

S. B. Ebrahimi. A bi-objective model for a multi-echelon supply chain design considering efficiency and customer satisfaction: a case study in plastic parts industry. The International Journal of Advanced Manufacturing Technology, 95(9):3631-3649, 2018. 
M. Eskandarpour, S. Zegordi, and E. Nikbakhsh. A parallel variable neighborhood search for the multi-objective sustainable post-sales network design problem. International Journal of Production Economics, 145(1):117-131, 2013.

M. Eskandarpour, E. Nikbakhsh, and S. Zegordi. Variable neighborhood search for the bi-objective post-sales network design problem: A fitness landscape analysis approach. Computers \& Operations Research, 52(B):300-314, 2014.

M. Eskandarpour, P. Dejax, J. Miemczyk, and O. Péton. Sustainable supply chain network design: an optimization-oriented review. Omega, 54:11-32, 2015.

M. Eskandarpour, P. Dejax, and O. Péton. A large neighborhood search heuristic for supply chain network design. Computers \& Operations Research, 80:23 - 37, 2017.

M. Eskandarpour, D. Ouelhadj, S. Hatami, A. A. Juan, and B. Khosravi. Enhanced multidirectional local search for the bi-objective heterogeneous vehicle routing problem with multiple driving ranges. European Journal of Operational Research, 277(2):479 - 491, 2019.

J. Freis, P. Vohlidka, and W. A. Günthner. Low-carbon warehousing: Examining impacts of building and intra-logistics design options on energy demand and the co2 emissions of logistics centers. Sustainability, 8(5), 2016.

S. Ganguly, N. Sahoo, and D. Das. Mono- and multi-objective planning of electrical distribution networks using particle swarm optimization. Applied Soft Computing, 11(2):2391 $2405,2011$.

J. Gao and F. You. Modeling framework and computational algorithm for hedging against uncertainty in sustainable supply chain design using functional-unit-based life cycle optimization. Computers \& Chemical Engineering, 107:221 - 236, 2017. 
515 K. Govindan, A. Jafarian, and V. Nourbakhsh. Bi-objective integrating sustainable order allocation and sustainable supply chain network strategic design with stochastic demand using a novel robust hybrid multi-objective metaheuristic. Computers $\& 3$ Operations Research, 62:112 - 130, 2015.

G. Guillén-Gosálbez. A novel milp-based objective reduction method for multi-objective optimization: Application to environmental problems. Computers \& Chemical Engineering, 35(8):1469 - 1477, 2011.

I. Harris, C. L. Mumford, and M. N. Naim. A hybrid multi-objective approach to capacitated facility location with flexible store allocation for green logistics modeling. Transportation Research Part E: Logistics and Transportation Review, 66(0):1 - 22, 2014.

H. Heggen, K. Braekers, and A. Caris. A multi-objective approach for intermodal train load planning. OR Spectrum, 40(2):341-366, Mar 2018.

R. Jamshidi, S. Fatemi Ghomi, and B. Karimi. Multi-objective green supply chain optimization with a new hybrid memetic algorithm using the taguchi method. Scientia Iranica, 19 (6):1876-1886, 2012.

D. K. Kadambala, N. Subramanian, M. K. Tiwari, M. Abdulrahman, and C. Liu. Closed loop supply chain networks: Designs for energy and time value efficiency. International Journal of Production Economics, 183(Part B):382 - 393, 2017.

A. A. Kovacs, S. N. Parragh, and R. F. Hartl. The multi-objective generalized consistent vehicle routing problem. European Journal of Operational Research, 247(2):441 - 458, 2015.

R. S. Kumar, A. Choudhary, S. A. K. I. Babu, S. K. Kumar, A. Goswami, and M. K. 
Tiwari. Designing multi-period supply chain network considering risk and emission: a multi-objective approach. Annals of Operations Research, 250(2):427-461, 2017.

F. Lehuédé, O. Péton, and F. Tricoire. A lexicographic minimax approach to the vehicle routing problem with route balancing. European Journal of Operational Research, 2019.

K. Lian, A. B. Milburn, and R. L. Rardin. An improved multi-directional local search algorithm for the multi-objective consistent vehicle routing problem. IIE Transactions, 48 (10):975-992, 2016.

S. Liao, C. Hsieh, and P. Lai. An evolutionary approach for multi-objective optimization of the integrated location-inventory distribution network problem in vendor-managed inventory. Expert Systems with Applications, 38(6):6768 - 6776, 2011.

M. T. Melo, S. Nickel, and F. Saldanha-da Gama. Facility location and supply chain management - a review. European Journal of Operational Research, 196(2):401-412, 2009.

Y. Molenbruch, K. Braekers, A. Caris, and G. V. Berghe. Multi-directional local search for a bi-objective dial-a-ride problem in patient transportation. Computers 8 Operations Research, 77:58 - 71, 2017. doi: https://doi.org/10.1016/j.cor.2016.07.020.

L. A. Moncayo-Martínez and E. Mastrocinque. A multi-objective intelligent water drop algorithm to minimise cost of goods sold and time to market in logistics networks. Expert Systems with Applications, 64:455 - 466, 2016.

OECD/IEA. $\mathrm{CO}_{2}$ emissions from fuel combustion 2012-highlights. Technical report, OECD/IEA, 2012. URL https://www.iea.org/co2highlights/co2highlights.pdf. (accessed March 28, 2014). 
E. Olivares-Benitez, R. Ríos-Mercado, and J. González-Velarde. A metaheuristic algorithm to solve the selection of transportation channels in supply chain design. International Journal of Production Economics, 145(1):161-172, 2013.

M. S. Pishvaee, R. Zanjirani Farahani, and W. Dullaert. A memetic algorithm for bi-objective integrated forward/reverse logistics network design. Computers \&3 Operations Research, 37 (6):1100 - 1112, 2010.

D. Pisinger and S. Ropke. Large neighborhood search. In M. Gendreau and J.-Y. Potvin, editors, Handbook of Metaheuristics, pages 399-419. Springer New York, 2nd edition, 2010.

J. M. Ries, E. H. Grosse, and J. Fichtinger. Environmental impact of warehousing: a scenario analysis for the united states. International Journal of Production Research, 55(21):64856499, 2017.

J. O. Robles, S. D.-L. Almaraz, and C. Azzaro-Pantel. Optimization of a hydrogen supply chain network design by multi-objective genetic algorithms. In Z. Kravanja and M. Bogataj, editors, 26th European Symposium on Computer Aided Process Engineering, volume 38 of Computer Aided Chemical Engineering, pages 805 - 810. Elsevier, 2016.

B. L. Shankar, S. Basavarajappa, J. Chen, and R. Kadadevaramath. Location and allocation decisions for multi-echelon supply chain network - a multi-objective evolutionary approach. Expert Systems with Applications, 40(2):551 - 562, 2013a.

B. L. Shankar, S. Basavarajappa, R. Kadadevaramath, and J. Chen. A bi-objective optimization of supply chain design and distribution operations using non-dominated sorting algorithm: A case study. Expert Systems with Applications, 40(14):5730 - 5739, 2013b.

P. Shaw. Using constraint programming and local search methods to solve vehicle routing 
problems. In Proceedings of the 4th International Conference on Principles and Practice of Constraint Programming, pages 417-431, 1998.

J. Shi, Z. Liu, L. Tang, and J. Xiong. Multi-objective optimization for a closed-loop network design problem using an improved genetic algorithm. Applied Mathematical Modelling, 45: $14-30,2017$.

E. Tappia, G. Marchet, M. Melacini, and S. Perotti. Incorporating the environmental dimension in the assessment of automated warehouses. Production Planning and Control, 26(10):824-838, 2015.

A. Tiwari, P.-C. Chang, M. Tiwari, and R. Kandhway. A hybrid territory defined evolutionary algorithm approach for closed loop green supply chain network design. Computers $\&$ Industrial Engineering, 99:432 - 447, 2016.

F. Tricoire. Multi-directional local search. Computers $\&$ Operations Research, 39(12):3089 3101, 2012.

C. Waltho, S. Elhedhli, and F. Gzara. Green supply chain network design: A review focused on policy adoption and emission quantification. International Journal of Production Economics, 208:305 - 318, 2019.

F. Wang, X. Lai, and N. Shi. A multi-objective optimization for green supply chain network design. Decision Support Systems, 51(2):262-269, 2011.

R. Zanjirani Farahani, M. SteadieSeifi, and N. Asgari. Multiple criteria facility location problems: A survey. Applied Mathematical Modelling, 34(7):1689 - 1709, 2010.

S. Zhang, C. K. M. Lee, K. Wu, and K. L. Choy. Multi-objective optimization for sustainable supply chain network design considering multiple distribution channels. Expert Systems with Applications, 65:87 - 99, 2016. 
Y. Zhang, S. Liu, and X. Zhang. An optimized supply chain network model based on modified genetic algorithm. Chinese Journal Of Electronics, 3(2):468-476, 2017.

605 E. Zitzler, L. Thiele, M. Laumanns, C. Fonseca, and V. da Fonseca. Performance assessment of multiobjective optimizers: an analysis and review. IEEE Transactions on Evolutionary Computation, 7(2):117 - 132, 2003. 